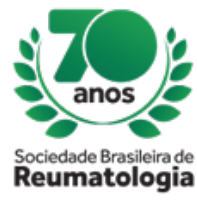

\title{
POLYARTERITIS NODOSA MANIFESTING AS PARANEOPLASTIC SYNDROME
}

Elisa Fernandes de Melo (Universidade de Taubaté, Taubaté, SP, Brasil), Vinicius Verlangieri Soubihe (Universidade de Taubaté, Taubaté, SP, Brasil), Raylane Shellyda de Almeida Anate (Universidade de Taubaté, Taubaté, SP, Brasil), Natália Engler Ravasio (Universidade de Taubaté, Taubaté, SP, Brasil), Amauri Marcelo Cisotto Rocha Junior (Universidade de Taubaté, Taubaté, SP, Brasil), Paulo Giovanni Estevam (Universidade de Taubaté, Taubaté, SP, Brasil), Larissa Almeida Campos Esteves (Universidade de Taubaté, Taubaté, SP, Brasil), Drielle Rezende Pavanitto (Universidade de Taubaté, Taubaté, SP, Brasil), Aline Gimenez Guerra (Universidade de Taubaté, Taubaté, SP, Brasil)

\section{BACKGROUND}

Polyarteritis nodosa (PAN) is a systemic necrotizing vasculitis with a predilection for the arteries of medium and small caliber. The diagnosis of any vasculitis should be carried out in a judicious manner, always resorting to the possibility of differential diagnoses. Even when confirmed, there is the possibility of being secondary to neoplasms, infections and drug exposures. The pathogenesis of paraneoplastic syndrome is due to secretions of substances such as hormones or immune-mediated mechanisms. They may appear before, after or concomitantly with the neoplasm, but about $71 \%$ of the cases occur before tumor discovery or during recurrence. Due to the rareness of the association between PAN and paraneoplastic syndrome and because it is related to a worse prognosis, the occurrence of this association should be reported.

\section{CASE REPORT}

A 43-year-old woman, smoker (20 pack-years) reported Raynaud's phenomenon for 4 years, evolving to livedo reticularis in the past 6 months associated with weight loss of $6 \mathrm{Kg}$ and lack of appetite. In the last 2 months presented painful blisters and cyanotic lesions at extremities (figure 1 ) and a sudden reduction of visual acuity. Central venous occlusion of the retina was observed bilaterally in the ophthalmologic evaluation. It evolved with worsening and ascendant and loss of peripherical pulses. Complete blood count showed chronic disease's anemia, leukocytosis, increased inflammatory tests and normal renal function. Performed ANCA, ANA, anti-Ro, anti-CCP, serology for HIV, hepatitis B and C all with negative results. Initiated antibiotic therapy, anticoagulation, pulse therapy with cyclophosphamide and methylprednisolone, and immunoglobulin. An attempt was made for surgical debridement, evolving with mummification of the forearm and legs, and due to the infeasibility, amputation was chosen. A biopsy showed septal panniculitis associated with arteritis in medium-caliber vessels. Due to the refractoriness of the immunosuppressive treatment, the hypothesis of polyarteritis nodosa secondary to paraneoplastic syndrome was proposed. Investigation of the primary site was started, with probable pulmonary focus, however after 45 days of hospitalization, the patient died.

\section{CONCLUSION}

PAN is a vasculitis with clinical diagnostic criteria, according to the American College of Rheumatology, but whenever possible, it should be confirmed by biopsy. If not treated, it is usually lethal. In addition, the lack of clinical response to treatment may be an alert to think of a secondary cause, such as paraneoplastic. 